18. Ver nota 2.

19. "O homem é livre na exata medida em que tem o poder para existir e agir segundo as leis da natureza humana [...]. A liberdade não tira, mas põe a necessidade do agir." Cf. Spinoza, Tratado Político, cap II $§ 7$ e 11.

\section{BREVES CONSIDERAÇÕES SOBRE A METAFÍSICA DE LEIBNIZ}

Resumo: Neste texto, pretendemos fazer uma breve análise da metafísica leibniziana, tomando como fio condutor a noção de substância individual — que desembocará no conceito de mônada - , de sorte a tentar acentuar algumas de suas implicações e pressupostos. Passando pela criação e pelo sistema de determinação universal que ela acarreta, pretendemos mostrar de que maneira a substância é como que um espelho de todo o universo, a fim de mostrar sua relação com o restante das substâncias e, particularmente, explicitar aquilo que Leibniz denominará “corpo orgânico", tentando resolver o clássico problema da união da alma e do corpo.

Palavras-chave: metafísica, mônada, expressão, união substancial, corpo orgânico.

Poucas teses leibnizianas causaram tanto estranhamento - que o diga Arnauld! - quanto a enunciada no $§ 13$ do Discurso de Metafísica: "a noção duma substância individual encerra, duma vez por todas, tudo quanto the pode acontecer" (LEIBNIZ 8, p. 128). Para compreendê-la, todavia, devemos primeiramente precisar em que consiste a noção de uma substância individual. "É correto, diz Leibniz, quando se atribui grande número de predicados a um mesmo sujeito e este não é atribuído a nenhum outro, chamá-lo substância individual” (LEIBNIZ 8, p. 124). Mas tal definição, apenas nominal, não é suficiente para saber de que maneira o 
sujeito suporta seus predicados. A identidade e a independência do sujeito são apenas postuladas. Ora, é da natureza da verdade o fato de que, em toda proposição verdadeira — seja ela universal ou singular, necessária ou contingente - , o predicado está, de alguma forma, contido no sujeito. Assim, "podemos dizer que a natureza de uma substância individual ou de um ser complexo consiste em ter uma noção tão perfeita que seja suficiente para compreender e fazer deduzir de si todos os predicados do sujeito a que se atribui esta noção" (LEIBNIZ 8, p. 124). Se, segundo o princípio dos indiscerníveis, duas substâncias não podem diferir solo numero; se deve existir uma razão a priori que garanta que um sujeito seja sempre idêntico ${ }^{1}$ e independente, é necessário, então, que a substância individual envolva, de direito, todos os seus predicados - e não se exige aqui outra ligação que "aquela que se encontra a parte rei entre os termos de uma proposição verdadeira" (LEIBNIZ 4, p. 64). Examinemos melhor como se dá essa ligação.

Uma das consequências fundamentais da natureza da verdade é o princípio de razão suficiente, i.e., que nada acontece sem razão ou que não há efeito sem causa. $\mathrm{O}$ nexo entre predicado e sujeito constitui justamente a razão de uma verdade (LEIBNIZ 5, p.576). Segue-se disso que a noção completa de uma substância constitui a razão de todos os predicados que se lhe atribuem, de sorte que a passagem de um predicado a outro tem sua origem na própria substância, não havendo, portanto, denominações extrínsecas. Isto, porém, permanece ainda uma explicação bastante parcial. Vale lembrar, seguindo a análise de Deleuze, que o predicado não é um atributo, mas relação ou acontecimento (Leibniz às vezes também usa "fenômeno" como sinônimo). A conexão existente entre o sujeito "eu" e um predicado qualquer é sempre a de uma ação, de uma modificação, sendo o sujeito, consequentemente, definido como a unidade da série infinita de suas modificações, e não mais como um núcleo essencial incompleto ao qual se acrescentariam — e também se subtrairiam - predicados meramente acidentais: “o que está incluído na noção como sujeito é sempre um acontecimento marcado por um verbo ou uma relação marcada por uma preposição: escrevo, vou à Alemanha, atravesso o Rubicão..." (DELEUZE 2, p. 93). Dada a independência da substância face a todas as outras — com exceção de Deus, como veremos adiante —, é necessário que ela seja causa (e razão a priori) de todas as suas modificações, que haja um princípio interno de ação que, não apenas garanta a passagem de uma ação à outra, mas que também assegure uma diferença intrínseca, qualitativa de uma substância em relação a todas as outras, como o exige o princípio dos indiscerníveis. Com efeito, unidade e força (i.e., espontaneidade, tendência à ação) serão, na metafísica leibniziana, os componentes fundamentais da substancialidade.

Assim, podemos entender, ao menos parcialmente, de que maneira, no último período de sua obra, Leibniz chega ao conceito de mônada, enquanto substância simples e "sem janelas", imortal e imperecível. Ora, sendo a matéria atualmente subdividida ao infinito ${ }^{2}$, é preciso que haja verdadeiras unidades, posto que a multiplicidade pressupõe a unidade. Logo, não tendo partes, a substância (ou mônada) não pode começar e acabar senão por criação e aniquilamento, visto que todo composto é formado pelo agregado de substâncias simples, que devem necessariamente subsistir. Da mesma forma, toda modificação do composto decorre das mudanças entre as partes, de sorte que uma substância simples, dotada de verdadeira unidade, só pode modificar-se a partir de si mesma, sem qualquer influência externa, diferindo cada uma de todas as outras por suas qualidades intrínsecas (LEIBNIZ 9, p. 105).

Entretanto, tudo isso permanecerá abstrato enquanto nossa análise se restringir à substância em si, tomada isoladamente. Vimos que a noção completa é a razão da série de predicados que a constituem. Todavia, será 
em vão que procuraremos na própria substância a razão suficiente de sua existência — "as razões, portanto, do mundo, dirá Leibniz, acham-se em algum ser extramundano, diverso da cadeia dos estados ou da série das coisas, cujo agregado constitui o mundo" (LEIBNIZ 7, p. 156). Pois, ainda que um estado provenha do anterior, é preciso que exista algum Ser necessário (cuja essência envolve a existência) que constitua a razão última de toda a série do mundo e que esteja, consequentemente, fora dela, qual seja, Deus. Esse ser necessário, sendo absolutamente perfeito, concentra em si todas as perfeições no grau supremo, "donde se segue que Deus, possuindo suprema e infinita sabedoria, age de forma mais perfeita, não só em sentido metafísico mas também moralmente falando" (LEIBNIZ 8, p.

119). Isso posto, como entender a criação do mundo nesses termos?

Na medida em que Deus é a fonte de tudo o que existe, é necessário que as essências tenham certa realidade em seu entendimento, pois, não só a razão suficiente do mundo criado se encontra em Deus, como também é impossível que algo que exista tenha sua origem no nada, de tal sorte que um existente só pode provir de outro existente (LEIBNIZ 7, p. 157). Ora, a principal condição para que algo exista, mesmo enquanto essência no entendimento divino, é que este algo seja possível, quer dizer: não contraditório em si e suscetível de uma definição real. E, "pelo simples fato de que alguma coisa existe antes do que nada, há nas coisas possíveis ou na própria possibilidade, ou essência, certa exigência de existência, ou (digamos) uma pretensão a existir e, resumindo numa palavra, o fato de a essência por si só tender à existência" (LEIBNIZ 7, p. 156). Analisemos melhor esse ponto. Vimos que a possibilidade é o princípio da essência. Entretanto, se todo possível tende à existência, não se compreende muito bem por que existe $x$ de preferência a $y$, pois, uma vez que nem todo possível se torna ato, é necessário que haja uma razão que determine a existência efetiva de $x$ e a inexistência de $y$ senão enquanto possível.
Leibniz continua a citação da seguinte maneira: "Donde, portanto, se segue que todas as coisas possíveis, ou que exprimem a essência ou realidade possível, tendem com igual direito à existência conforme a quantidade da essência ou realidade, ou conforme o grau de perfeição que envolvem, pois a perfeição nada mais é que a quantidade da essência" (Ibid., grifo meu). Assim, define-se como princípio da existência a perfeição, isto é, a quantidade de essência. Para compreender melhor a perfeição, sigamos a interpretação proposta por Belaval (BELAVAL 1, pp. 393-98): a perfeição pode ser analisada de acordo com dois vieses, a saber, o quantitativo e o qualitativo — ou ainda, através da aritmética dos números finitos e a aritmética dos infinitos. O primeiro estabelece a comparação entre a essência e o número, na medida em que ambos podem ser concebidos como uma coleção de unidades, de tal sorte que não seria possível acrescentar-lhe ou subtrair-lhe nada sem destruir sua identidade. Portanto, a essência A, definida pelo conjunto de predicados $\{\mathrm{P} 1, \mathrm{P} 2, \mathrm{P} 3 \ldots \mathrm{Pn}\}$ seria menos perfeita que a essência $\mathrm{B}$, definida pelo conjunto de predicados $\{\mathrm{P} 1$ ', P2', P3'... Pn', Pn' +1$\}$, visto que o grau de perfeição se refere ao número de predicados contidos em sua essência, proporcionando um princípio de variedade. Ora, o viés quantitativo é ainda bastante insuficiente para precisar os graus de perfeição de uma essência, pois, aqui, é preciso distinguir: ainda que tanto nas verdades necessárias quanto nas contingentes, o predicado esteja sempre contido no sujeito, as primeiras possuem um número finito de predicados, de modo que é possível demonstrá-la através da redução aos idênticos; ao passo que as últimas possuem um número infinito de predicados, de modo que a demonstração é impossível de direito, prosseguindo a análise ao infinito ${ }^{3}$. Uma noção existencial — tal como a de uma substância individual —, é contingente, uma vez que seu contrário não implica contradição (ver-se-á isso mais detalhadamente adiante). É aqui que entra o viés qualitativo da 
perfeição: não se trata mais de pensar a essência “sicut numerus, mas como fons praedicatorum”, como uma série infinita cuja lei própria determina a produção de seus infinitos predicados. "Uma essência não é mais uma coleção de predicados na qual a forma manteria o todo, ela é uma série de predicados produzidos em ordem pelo todo que constitui sua lei. A estática se dinamiza. A lei de formação faz parte da essência do mesmo modo que os termos. (...) Assim como a Aritmética dos números finitos põe o acento sobre o múltiplo, sobre a coleção de unidades, enfim, um princípio de variedade, da mesma forma a Aritmética dos infinitos põe o acento sobre a lei da série, princípio de uniformidade. Uma coisa é tanto mais perfeita quanto mais ordenada, mais regular ela for. Unindo-se os dois princípios, nós reencontramos a idéia de harmonia de onde o próprio Leibniz partiu: a perfeição é a harmonia, o consensus in majore varietate" (BELAVAL 1, p. 395) ${ }^{4}$.

Estamos, agora, em condições de avançar em nossa análise. Dizíamos, mais acima, que a substância individual não pode ser considerada isoladamente. E isso se dá porque não basta que algo seja possível para existir, mas é preciso que seja também compossivel, isto é, compatível com o conjunto das séries que formam o mundo. Se o possível se define como não contradição em si, o compossível é a não contradição entre os possíveis que compõem um conjunto. É isso que Leibniz insistia em frisar a Arnauld: Deus não cria um "Adão vago", mas sim um mundo no qual existe um Adão particular, que pecará, que terá tantos filhos etc. Não é contraditório pensar em um Adão que não houvesse pecado, mas tal essência faria parte de um outro mundo possível, e não deste mundo possível efetivamente criado, pois há uma relação de determinação recíproca entre um termo e o conjunto do qual ele faz parte. Assim, a doutrina da noção completa agora adquire maior consistência: sem noção completa, não pode haver compossibilidade — " 'sem uma noção 'perfeita' que envolva todos os predicados passados, presentes e futuros de cada substância, seria impossível para Deus decidir em função de um saber totalmente determinante: as substâncias viriam à existência isoladamente e colocarse-ia o problema de sua 'ligação' post festum. (...) Sem noção perfeita, a compossibilidade não significaria nada, e, sem compossibilidade, o 'mundo' daria lugar a uma soma de decretos caprichosos" (MOURA 16, p. 67), o que é pouco conforme à perfeição divina. Com efeito, Deus, comparando as infinitas combinações de possíveis, escolhe a mais perfeita, isto é, o conjunto de compossíveis mais harmônico, no qual há o máximo de essência possível. Seria contraditório afirmar que Deus escolhe criar o mundo sem nenhuma razão - mais ou menos como o fazia Descartes, ao admitir a possibilidade de uma vontade independente criadora de seus próprios motivos - , pois não há vontade que não pressuponha motivos - e, no caso de Deus, sua vontade é sempre orientada por sua perfeição (BELAVAL 1, p. 390). Dessa forma, entende-se que Deus é, não apenas a causa eficiente, mas também a causa final do mundo criado.

Mas, se é assim, como se dá a relação entre o mundo e as mônadas? Em muitos textos, Leibniz dirá que, não apenas a substância contém em si tudo o que lhe deve ocorrer, mas também tudo o que ocorreu, ocorre e ocorrerá em todo o universo, o qual ela exprime do seu ponto de vista. Vá lá que, em virtude da determinação integral do mundo criado, os predicados tenham que estar contidos no sujeito, mas é, no mínimo, curioso esse complemento que Leibniz lhe dá. Dada a condição de "clausura" da mônada (ela não tem janelas, é causa de todas as suas modificações, supremamente independente diante de todas as outras), seria realmente difícil compreender de que maneira as mônadas se relacionam entre si. Então, seria a expressão apenas uma relação "forjada", um artifício para dar conta dessa dificuldade? Não se trata disso. Ora, é evidente, pelo que acabamos de ver sobre a criação, que o mundo, enquanto conjunto de 
fenômenos, preexiste, de direito, às substâncias criadas — ainda que, como veremos, ele seja apenas uma virtualidade que só existe atualmente nas mônadas que o exprimem. Da mesma forma, encerrando o máximo de realidade na maior ordem - formando, no sentido tradicional, um cosmos que proporciona uma variação infinita —, é preciso que tudo seja contínuo, de tal sorte que não se pode admitir qualquer descontinuidade no sistema de fenômenos: "o movimento local, para Descartes, pode ser interrompido por seu contrário, o repouso absoluto, enquanto que o movimento-processo, para Leibniz, não pode, desvanecendo-se e pela passagem ao limite, dar senão a aparência de repouso. Se tudo se liga, não é somente no instante; e, de resto, os instantes não são independentes entre si (...). Se tudo se liga na duração, isso quer dizer que a toda variação da causa deve, em virtude da lógica da expressão, corresponder uma variação proporcional do efeito" (BELAVAL 1, p. 384). Mas qual a relação que esse cosmos tem com as substâncias? É que Deus, ao criar o mundo, seguindo a lei de continuidade, "faz com que o resultado de cada visão do universo, enquanto contemplado de certa maneira, seja uma substância expressando o universo segundo esse relance" (LEIBNIZ 8, p.130), de tal maneira que cada substância é como "um centro ou ponto no qual, por mais simples que seja, existem uma infinidade de ângulos formados pelas linhas que para ele convergem"(LEIBNIZ 15, p. 154). Assim, ao continuum do mundo criado pertencem infinitos pontos pré-individuais — cuja transição de um a outro é insensível, implicando certa distância, mas jamais a descontinuidade — nos quais se situarão, em cada um, uma substância, formando um ponto de vista sobre o todo, sendo o ponto de vista a condição de representação do universo enquanto série convergente de todas as séries: "o ponto de vista, o vértice do cone, é a condição sob a qual é apreendido o conjunto da variação das formas ou a série das curvas do segundo grau. Não basta nem mesmo dizer que o ponto de vista apreende uma perspectiva, um perfil que a cada vez apresentaria a cidade à sua maneira, pois ela também faz com que apareça a conexão de todos os perfis entre si, a série de todas as curvaturas ou inflexões. O que se apreende de um ponto de vista não é, pois, nem uma rua determinada nem sua relação determinável com as outras ruas, que são constantes, mas a variedade de todas as conexões possíveis entre percursos de uma rua qualquer a outra: a cidade como labirinto ordenável. A série infinita das curvaturas ou inflexões é o mundo, e o mundo inteiro está incluído na alma sob um ponto de vista" (DELEUZE 2, p. 48, grifos meus). Portanto, o mundo é como que o horizonte comum (virtual) de todas as substâncias, mas só existe atualmente nelas a partir da relação expressiva que elas mantêm entre si (prolongamento analítico de cada série em todas as outras, como dizia Deleuze), de modo que há uma correspondência entre os fenômenos de cada mônada. "Dizemos que exprime uma coisa aquilo em que existem os modos correspondentes aos modos da coisa a ser expressa. (...) Donde se conclui não ser necessário que aquilo que exprime seja semelhante à coisa expressa, contanto que se conserve alguma analogia dos modos" (LEIBNIZ 10, p. 165). E, se o efeito exprime a causa, todas as criaturas exprimem Deus, sem, contudo, serem a ele inteiramente semelhantes há, entretanto, uma relação regrada e proporcional (expressão) que faz com que o infinito seja "refletido" nas criaturas finitas, garantida pela contínua ação de Deus sobre nós. É justamente essa a função da retomada que Leibniz faz da reminiscência de Platão. O infinito existe em nós virtualmente - no entanto, a atualização dessas virtualidades, garantida pela natureza representativa da alma, só pode se desenvolver através do tempo, dada a limitação inevitável de toda criatura ${ }^{5}$.

Assim, é preciso aprofundar a consideração parcial que fizemos do conceito de mônada, pois, mesmo com tudo o que dissemos até aqui, ainda não se pode compreender de que maneira é possível falar em ação 
de uma substância, menos ainda de que maneira elas agem entre si. Ora, no Discurso de Metafísica, antes mesmo de Leibniz introduzir tal conceito, já se afirmava explicitamente que "nada pode acontecer-nos além de pensamentos e percepções, e todos os nossos futuros pensamentos e percepções não passam de consequências, embora contingentes, dos nossos pensamentos e percepções anteriores" (LEIBNIZ 8, p. 130). Dizíamos, mais acima, que os predicados (relações, acontecimentos, fenômenos), em sua conexão ao sujeito, constituem sempre uma ação e que há um princípio interno de ação em cada substância. Podemos, agora, colocar isso na terminologia do último período da obra leibniziana: a ação de uma mônada consiste na percepção (representação do múltiplo no uno), e o princípio interno que realiza as passagens ou tendências de uma percepção a outra consiste na apetição (LEIBNIZ 15, p. 153). No entanto, deve-se distinguir entre percepção e apercepção: com efeito, as mônadas, por serem finitas, só podem exprimir o universo, que é infinito, confusamente. Há uma infinidade de pequenas percepções (ou percepções insensíveis) envolvidas em cada estado da alma e, por nossa limitação, não podemos nos aperceber senão de algo que decorre das relações entre todas essas percepções insensíveis — "são elas que formam este não sei quê, esses gostos, essas imagens das qualidades dos sentidos, claras no conjunto, porém confusas nas suas partes individuais, essas impressões que os corpos circunstantes produzem em nós, que envolvem o infinito, esta ligação que cada ser possui com todo o resto do universo" (LEIBNIZ 11, p. 12). Por exemplo, podemos ouvir o som de uma multidão sem perceber distintamente cada uma das vozes que o compõem. No entanto, não se trata de uma mera relação partestodo (devido ao hábito, e.g., o todo pode se tornar para nós insensível também), mas sim da distinção entre o notável e o ordinário: "pois aquilo que é notável deve estar composto de partes que não são notáveis; nada pode nascer de repente, nem o pensamento nem o movimento" (LEIBNIZ
11, p. 68). Havíamos dito, acima, que não há descontinuidade, mas necessariamente transições graduais. A lei de continuidade, que estabelece a ligação de tudo na duração, também se coloca aqui: sejam A, B e C três estados sucessivos de uma alma; tomemos B como o estado presente; havia em A uma infinidade de pequenas percepções que "preparavam"o estado $\mathrm{B}$, assim como neste há uma infinidade de pequenas percepções que "preparam" o estado C — não há lacunas entre os estados da alma, de sorte que cada estado decorre natural e espontaneamente de outro, sem necessidade de qualquer interferência exterior (tudo na alma decorre de seu próprio fundo, diria Leibniz). No entanto, como Leibniz o lembrava a Bayle, cumpre distinguir entre o espontâneo e o voluntário (LEIBNIZ 13, p.65), pois só assim se pode compreender como uma substância pode dar a si mesma uma sensação de dor logo após experimentar uma sensação de prazer. "Como uma dor sucederia a um prazer, se mil pequenas dores, ou melhor, semidores que vão reunir-se na dor consciente, já não estivessem dispersas no prazer? Por mais bruscamente que eu dê uma paulada no cachorro que está comendo, ele terá tido as pequenas percepções da minha chegada em surdina, do meu odor hostil, da elevação do pau, percepções que sustentam a conversão do prazer em dor" (DELEUZE 2, p.150). Evidentemente, o cachorro não escolheu sentir a dor, mas a dor se lhe sucedeu espontaneamente das infinitas percepções insensíveis que já se encontravam nele no momento em que comia e sentia prazer.

No entanto, aqui surgem dois problemas: se a dor que o cachorro sente se origina dele próprio, por que ele a percebe como provindo da paulada que recebeu de uma pessoa? E, ainda, um dos problemas fundamentais que tanto inquietavam o século XVII: como a uma afecção do corpo (a paulada) corresponde um sentimento da alma (a dor) - em outras palavras, como a alma e o corpo se relacionam? Quanto ao primeiro problema, é preciso entrecruzar a lei de continuidade com a entre-expressão 
monadológica. Ora, se cada mônada é como um espelho vivo de todo o universo (o mesmo universo para todas elas), é preciso que o estado atual de uma corresponda, de alguma forma, ao estado atual de todas as outras. No entanto, como elas só o exprimem confusamente, apenas uma pequena porção é percebida mais distintamente, que é aquela que lhe está mais próxima ${ }^{6}$. Assim, há diferentes graus de expressão e, no conjunto de fenômenos do mundo, é a entre-expressão que vai diferenciando ao infinito as mônadas, na medida em que é preciso haver uma proporção entre a expressão de cada mônada, uma vez que trata-se de pensar um conjunto de compossíveis: "desta forma é concebível, portanto, a intromissão ou mútua limitação das substâncias e, por conseguinte, neste sentido pode-se afirmar que elas agem umas sobre as outras, sendo por assim dizer obrigadas a acomodar-se entre si, pois pode suceder que uma modificação aumente a expressão de uma, diminuindo a de outra" (LEIBNIZ 8, p. 131). Então, ação e paixão, além de se determinarem reciprocamente, consistem não em uma influência real, mas ideal, correspondente ao acréscimo ou diminuição do grau de expressão — ou seja, diz-se que age uma substância cujo grau de expressão é maior, de modo que a razão a priori de tal fenômeno se encontra nela; ao passo que padece aquela substância cujo fenômeno tem sua razão a priori em outra, de modo que seu grau de expressão é menor. Isso não é tudo, mas para aprofundar a análise precisaremos entrar um pouco no segundo problema. O ponto de vista da alma, de que tanto falamos, é o seu corpo próprio: “embora cada Mônada criada represente todo o universo, representa mais distintamente o corpo que lhe está afeto e de que constitui a Enteléquia; e como esse corpo exprime todo o universo, pela conexão de toda a matéria no pleno, a alma representa também todo o universo ao representar esse corpo que lhe pertence de um modo particular" (LEIBNIZ 9, p. 111). Assim, a zona clara de expressão de uma mônada é o seu corpo, segundo as relações que este possui com outros corpos. Não se trata, porém, de um mero agregado, mas de uma verdadeira substância corpórea. Essa substância, ela é composta de infinitas mônadas, mas o que a distingue de um agregado é o fato de que há uma mônada dominante (ou enteléquia), "sobressaindo-se" devido ao seu maior grau de expressão, que lhes garante a unidade de um organismo, isto é, máquina até em suas mais ínfimas partes: "cada substância simples ou Mônada distinta, que constitui o centro de uma substância composta (como, por exemplo, de um animal) e o princípio de sua unicidade, está rodeada por uma massa composta de uma infinidade de outras Mônadas, que constituem o corpo próprio desta Mônada central, a qual representa, segundo as afecções desse corpo, como em uma espécie de centro, as coisas que estão fora dela" (LEIBNIZ 15, p. 154). Entretanto, o segundo problema ainda persiste.

Leibniz elenca três maneiras distintas de conceber a união da alma e do corpo: 1) a via da influência, segundo a qual a alma age sobre o corpo e vice-versa, o que é logo afastado como absurdo; 2) a via das causas ocasionais, defendida por Malebranche, segundo a qual Deus faz com que a cada afecção do corpo corresponda uma sensação na alma, o que também é afastado por introduzir um Deus ex machina, ou um milagre perpétuo, em algo de todo ordinário e natural; 3) a via da harmonia preestabelecida, hipótese defendida por Leibniz, da qual trataremos agora (LEIBNIZ 14, pp. 45-8). Segundo tal hipótese, não há exatamente união, porém conformidade ou harmonia entre a alma e o corpo, que, no entanto, conservam certa independência. E isso decorre da própria natureza tanto da alma quanto do corpo, cada qual agindo segundo suas próprias leis, harmônicas entre si: os estados da alma, como já vimos, são expressões dos estados correspondentes do mundo e, particularmente, de seu corpo próprio, que é seu ponto de vista sobre o universo. "Pela noção de substância ou de ser completo em geral, que mostra que seu estado presente é sempre uma consequência natural de seu estado precedente, segue-se que a natureza 
de cada substância singular e, por conseguinte, de toda alma consiste em expressar o universo, e que foi criada desde o princípio de tal sorte que, em virtude das próprias leis de sua natureza, tem que concordar com o que sucede nos corpos e, particularmente, com o que se passa no seu". Para complementar, suponhamos o seguinte esquema:

\section{Estado do corpo no momento A Estado da alma no momento A \\ Estado do corpo no momento B Estado da alma no momento B (ferida)

Não foi a ferida que causou a dor, mas, cada qual seguindo suas próprias leis, houve uma correspondência entre o estado do corpo e o estado da alma; "portanto, posto que a ferida forma parte do estado do corpo no momento $\mathrm{B}$, a representação ou expressão da ferida, que é a dor, formará também parte da alma no momento B; pois assim como um movimento procede de outro movimento, de igual modo uma representação procede de outra representação em uma substância cuja natureza é ser representativa" (LEIBNIZ 4, pp.128-9). A alma age de acordo com o sistema de causas finais, enquanto os corpos, de acordo com o sistema das causas eficientes. Mas há uma perfeita harmonia entre eles, de modo que, não só se explica a união da alma e do corpo, como se percebe também o vínculo existente entre a metafísica e a física.

\section{BRIEF CONSIDERATIONS ON LEIBNIZ'S METAPHYSICS}

Abstract: In this text, we aim to analyse briefly Leibniz's metaphysics, taking as thread the notion of individual substance — that will lead into the concept of monad - in order to accentuate some of its implications and pressupositions. Passing through the creation and the universal determination system (that) it implies, we aim to show how is the substance a sort of mirror of all the universe, in order to show its relation with the rest of the substances and, in particular, to make explicit what Leibniz calls "organic body", trying to solve the classical problem of the union between body and soul.

Keywords: metaphysics; monad; expression; substantial union; organic body.

\section{REFERÊNCIAS BIBLIOGRÁFICAS}

1. BELAVAL, Y. Leibniz critique de Descartes. Paris: Gallimard, 1960.

2. DELEUZE, G. A dobra: Leibniz e o barroco. Campinas: Papirus, 1991.

3. __. Diferença e repetição. Rio de Janeiro: Graal, 2006.

4. LEIBNIZ, G. W. Correspondencia con Arnauld. Buenos Aires: Losada, 1946.

5.___. Escritos Filosoficos. Buenos Aires: Charchas, 1982.

6. ___ "Correspondência com Clarke" in: Leibniz/Newton — Os Pensadores. São Paulo: Abril Cultural, 1983.

7. __ .Da origem primeira das coisas" in: Leibniz/Newton — Os Pensadores. São Paulo: Abril Cultural, 1983.

8. . .Discurso de Metafísica" in: Leibniz/Newton — Os Pensadores. São Paulo: Abril Cultural, 1983.

9. _. . "Monadologia" in: Leibniz/Newton — Os Pensadores. São Paulo: Abril Cultural, 1983.

10. ___ “_ "O que é a idéia?” in: Leibniz/Newton — Os Pensadores. São Paulo: Abril Cultural, 1983.

11. Novos ensaios sobre o entendimento humano. Os Pensadores (II), São Paulo: Abril Cultural, 1984.

12. __ "Über die Freiheit" in: Leibniz, ed. Thomas Leinkauf. Munique: Diederichs, 1996.

13. . Esclarecimento das dificuldades encontradas por Bayle no Sistema novo da união da alma e do corpo" in: Sistema novo da natureza e da comunicação das substâncias e outros textos. Belo Horizonte: UFMG, 2002.

14. ___ "Observações acerca da harmonia da alma e do corpo" in: Sistema novo da natureza e da comunicação das substâncias e outros textos. Belo Horizonte: UFMG, 2002.

15. _. "Princípios da natureza e da graça fundados na razão" in: Discurso de Metafisica e outros textos. São Paulo: Martins Fontes, 2004.

16. Moura, C.A.R. de. "Contingência e Infinito" in: Racionalidade e crise. São Paulo: Discurso/UFPR, 2001. 


\section{NOTAS}

1. Cf. LEIBNIZ 4, pp.46-7: "Seja uma linha reta ABC que representa um determinado tempo. E seja uma substância individual, por exemplo, eu, que permaneço e subsisto durante esse tempo. Tomemos, pois, primeiramente a mim, que subsisto durante o tempo $\mathrm{AB}$, e também a mim, que subsisto durante o tempo BC. (...) Com efeito, se não houvesse nenhuma razão [que permitisse afirmar que sou eu que duro tanto em $\mathrm{AB}$ quanto em $\mathrm{BC}$ ], ter-se-ia tanto direito para dizer que é outra pessoa. É certo que minha experiência interior me convenceu a posteriori desta identidade, mas tem de haver também uma razão a priori. Ora, não é possível encontrar outra senão que tanto meus atributos do tempo e estados precedentes, assim como meus atributos e estados seguintes são predicados de um mesmo sujeito (...). Que quer dizer que o predicado está no mesmo sujeito senão que a noção do predicado se encontra de certa forma encerrada na noção do sujeito?"

2. O princípio de razão suficiente - aplicado à criação do mundo por Deus, como será desenvolvido adiante - exclui tanto o vazio quanto os átomos, visto existir mais perfeição (i.e., mais realidade, maior quantidade de essência) na matéria do que no vazio, e na matéria atualmente subdividida ao infinito, do que nos átomos finitos de Cordemoy. Além disso, contra os átomos, pode-se invocar o princípio dos indiscerníveis, uma vez que os átomos seriam apenas pequenas massas sem diferenças qualitativas entre si, de modo que uma coisa seria indiscernível de outra. Cf. LEIBNIZ, 1983, p.187: "Não é possível haver um princípio que determine a proporção da matéria, quer do pleno ao vazio, quer do vazio ao pleno. Dir-se-ia talvez que um deve ser igual ao outro; mas, como a matéria é mais perfeita que o vácuo, a razão exige que se observe a proporção geométrica, e que haja tanto mais pleno quanto mereça ser preferido. Mas, sendo assim, não haverá vácuo em absoluto, porque a perfeição da matéria está para a do vácuo como alguma coisa para nada. O mesmo se diga dos átomos. Com efeito, que razão se poderia aduzir para limitar a natureza no progresso da subdivisão?"

3. Chamemos ternário um número divisível por três, senário um número divisível por seis e duodenário um número divisível por doze. A proposição "todo número duodenário é senário" exprime uma verdade necessária, pois todo duodenário é binário-binário-ternário, sendo esta sua definição $(12=2 \cdot 2 \cdot 3)$, e todo binário-binárioternário é também binário-ternário, ou seja, senário $(6=2 \cdot 3)$, "pois 12 é o mesmo que $2 \cdot 2 \cdot 3$ - e $2 \cdot 2 \cdot 3$ é divisível por $2 \cdot 3$ e $2 \cdot 3$ é o mesmo que 6 - logo, 12 é divisível por 6". Cf. LEIBNIZ 12, p. 204, onde se segue: "Nas verdades contingentes, ainda que o predicado esteja contido no sujeito, ele não pode, porém, ser demonstrado como pertencente a este, de modo que aqui a proposição nunca será conduzida a uma equação ou identidade, sua resolução se prolonga ao infinito. Deus vê, não o fim da resolução - pois tal fim não existe —, mas a ligação (entre os termos) ou o modo pelo qual o predicado está encerrado no sujeito, pois ele vê tudo o que está contido na série."

4. Sobre o princípio de uniformidade, é exatamente o que Leibniz acentua a Bayle: "se agir uniformemente é seguir perpetuamente uma mesma lei da ordem ou de continuação — como no caso de certas séries ou seqüências de números —, admito que de si todo ser simples, e mesmo todo ser composto, age uniformemente". LEIBNIZ 13, p. 69

5. Cf. DELEUZE 3, p. 83: "No continuum de um mundo compossível, as relações diferenciais e os pontos notáveis determinam, pois, centros expressivos (essências ou substâncias individuais) nos quais, a cada vez, o mundo inteiro é envolvido de um determinado ponto de vista. Inversamente, estes centros se desenrolam e se desenvolvem, restituindo o mundo e desempenhando, então, o papel de simples pontos notáveis e de 'casos' no continuum exprimido. A lei de continuidade aparece aqui como uma lei das propriedades ou dos casos do mundo, uma lei de desenvolvimento que se aplica ao mundo exprimido, mas também às próprias mônadas no mundo; o princípio dos indiscerníveis é um princípio das essências, um princípio de envolvimento que se aplica às expressões, isto é, às mônadas e ao mundo nas mônadas.”

6. DELEUZE 2, p.49: "Por que há vários pontos de vista e várias almas irredutíveis, uma infinidade? Consideremos a série dos doze sons: ela é suscetível, por sua vez, de muitas variações não somente conformes a ritmos e melodias mas também de acordo com o movimento contrário ou retrógrado. Com mais razão, uma série infinita, mesmo que a variável seja única, é inseparável de uma infinidade de variações que a constituem: ela é necessariamente considerada de acordo com todas as ordens possíveis, privilegiando-se sucessivamente tal ou qual sequência parcial. É somente aí que uma forma, uma rua, recupera seus direitos, mas com relação à série inteira: cada mônada, como unidade individual, inclui toda a série; assim, ela expressa o mundo inteiro, mas não o faz sem expressar mais claramente uma pequena região do mundo, um 'departamento', um bairro da cidade, uma sequência finita. Duas almas não têm a mesma ordem, mas tampouco têm a mesma sequência, a mesma região clara ou iluminada." 